\title{
Pushing back the frontiers or still running around the same circles? 'Interpretative archaeoastronomy' thirty years on
}

\author{
Clive L. N. Ruggles \\ School of Archaeology and Ancient History, University of Leicester, \\ Leicester LE1 7RH, United Kingdom \\ email: rug@le.ac.uk
}

\begin{abstract}
This personal perspective on the development of archaeoastronomy over the last thirty years focuses on interpretative and methodological issues, picking up for example from the debate between Schaefer and Aveni at Oxford VII. How far we have actually progressed in the last three decades? Are we at last starting to achieve the correct fusion between the social science questions that our discipline addresses and the 'hard science' methods that are often involved in tackling them? In this paper I argue that the need for our hypotheses to be solidly grounded in social theory, which has rightly been recognised by most archaeoastronomers in recent years, is not an excuse for avoiding the need to be scientifically rigorous in assessing them against the actual evidence. I conclude that identifying robust methodologies for weighing together the different types of data with which the cultural astronomer is faced in different sitations, so as to infer the 'best' interpretation, remains at once the most challenging and the most pressing issue facing our 'interdiscipline' in the future.
\end{abstract}

Keywords. archaeoastronomy, ethnoastronomy, cultural astronomy, 'Oxford' conferences, theory, methodology, astronomical heritage

\section{Introduction}

Archaeoastronomy, like archaeology as a whole, is a science that asks social questions. Just as the archaeologist employs scientific techniques and procedures to examine the material remains of human activity in the past, so the archaeoastronomer applies a set of scientific and technological skills, relating mainly to positional astronomy and geomatics, in order to investigate spatial patterning within the material record and its possible relationship to astronomical phenomena. And, just like any archaeologist, the archaeoastronomer must invoke social theory in order to provide viable interpretations.

As a broad statement this may be satisfying but it is inadequate in that it relates only to archaeoastronomy in the 'pure' sense, where we are dealing with exclusively archaeological data. Even then it fails to acknowledge that spatial patterning (as epitomised by the study of putative astronomical 'alignments') is not the only way in which the archaeological record might reveal evidence of past human perceptions and actions relating to the skies and celestial phenomena. The term 'archaeoastronomy' has rightly come to define a field concerned not only with the disposition of monumental constructions and landscapes but also with artefacts, iconography, inscriptions, historical documentation, written accounts - in short, every conceivable form of data that might provide insights into thoughts and practices relating to astronomy in the past. Rightly, it is this 
broader field that has always concerned the 'Oxford' symposiał. Taken together with ethnoastronomy, which is concerned with contemporary practices relating to astronomy, particularly among modern indigenous societies, it is clear that the combined field of 'cultural astronomy' (Ruggles \& Saunders 1993b) has to deal with an extraordinarily wide range of scientific and cultural data and to work constantly to improve techniques for their collection, analysis, integration and interpretation.

In so far as 'cultural astronomy' is an endeavour practised by 'Western' academics, then it is still true to say that it is a science (in the broadest sense) asking social questions. However, in order to adequately 'bridge the gap' - to open up the discourse to those whose views of the world are of interest for the very reason that they themselves operate outside Western norms - we are forced to re-examine this whole approach. The shifts in focus that this may imply are of relevance not only to us as ethnographers but also as historians and archaeologists.

Archaeoastronomy is a field that has been struggling with its identity throughout the three decades since Oxford I first brought together the two schools of thought and practice that Aveni subsequently dubbed 'green' and 'brown' after the colours of the covers of the two Proceedings volumes. Is it a valid subdiscipline of anthropology that should be, if not actually yet being, theoretically well founded? Or should it be viewed more as a set of specialist techniques that should be applied by anthropologists, archaeologists or historians at large whenever they encounter a cultural issue that involves some reference to the sky? Is its public image a real threat to its viability or, as some have argued in these conferences, is the greatest problem the academics who, in entering the field, stray unwisely outside the disciplines in their own academic 'comfort zone' insufficiently aware of unfamiliar but nonetheless firm and well established frameworks of theory, method and practice? I shall give a personal view on these and related topics in what follows, also (in this written version) making reference, in the manner of an editorial, to some of the other papers presented in this volume.

\section{Thirty years on}

Archaeoastronomy and ethnoastronomy are burgeoning. In terms of the quantity of new data being collected and the breadth of new interpretations being provided, one need look no further than the pages of Archaeoastronomy. The Journal of Astronomy in Culture or Journal for the History of Astronomy, the annual publications of the conferences of the European Society for Astronomy in Culture, SEAC (see the SEAC website www . archeoastronomy . org for a full list), or the recent issue of the Journal of Cosmology devoted to cultural astronomy (Malville \& Holbrook 2010), let alone the many papers and books published among the wider literature on archaeology, history and anthropology.

There is no shortage of new 'discoveries' and even spectacular new types of discovery, such as the all-year-round solar observation devices at Taosi in China (Xu \& He 2010) and Chankillo in Peru (Ghezzi \& Ruggles 2007), the latter of which is still in a 'functioning state' even today. Such 'discoveries' still have the power to excite widespread public interest, as do some less tangible factors, the most prominent one at the moment being the run-up to the 2012 Mayan era-completion date.

However, as regards what we actually hope to achieve by what we are doing and (hence) why and how we are doing it, there is room for concern that in many ways we have not

$\dagger$ The Oxford conference publications are Heggie (1982) and Aveni (1982) [Oxford I]; Aveni (1989) [Oxford II]; Ruggles (1993) and Ruggles \& Saunders (1993a) [Oxford III]; Fountain \& Sinclair (2005) [Oxford V]; Esteban \& Belmonte (2000a; 2000b) [Oxford VI]; Bostwick \& Bates (2006) [Oxford VII]; and Vaiškūnas (2008) [Oxford VIII]. 
really moved on as much as we should have done in the last twenty or thirty years. To what extent have we actually improved the quality of our interpretations or advanced our methodologies? To what extent are practitioners of archaeoastronomy actually 'running round the same circles' rather than pushing back the frontiers of the 'interdiscipline'?

One can approach these questions in various ways. For instance, following McCluskey (this volume, pp. 19-29), one can measure the extent to which we have achieved a more balanced focus on context as well as content - or, as he puts it, on 'external' as well as 'internal' history. In the case of Babylonian studies, according to Steele (pp. 331-341), the sort of ('external') analysis contained in his excellent case study is only now possible because of the extensive ('internal') groundwork involved in the technical analysis and reconstruction of Babylonian mathematical astronomy during the last century. The extent to which the 'external' should be predicated on the 'internal'-and, indeed, the extent to which the opposite is the case - is much more debateable through most of archaeoastronomy. Nonetheless, there has certainly been a significant "social contextualisation" (Ruggles \& Urton 2007: 2) across the board in the past few decades, and this is evident in many of the papers in this volume that contextualise astronomical practices in terms of such factors as war and political power just as much as the more obvious seasonal calendars and festivals.

On the other hand, a few seemingly endless debates bog us down. One is the matter of terminology. Cross-disciplinarity has, of course, always led to terminological confusionsfor instance, the anthropological concept of 'cosmology' has become more or less familiar to astronomers, but they may be less clear about the distinction between cosmology, cosmovision and world-view (e.g. López, this volume, p. 45; Broda, p. 409) and they well may find the social scientist's usage of words like 'field', 'space' and 'universe' (e.g. Iwaniszewski, pp. 30-37; López, pp. 38-49) particularly strange and confusing-but these are surmountable with knowledge and experience. The problem is more with terms like 'observatory', which is still redolent of sites devoted exclusively to astronomical observations made by ancient astronomers created in the image of modern scientists. There is really no need to continue debating the meaning of such terms among ourselves: this no longer being the 1970s, surely we may assume that all serious cultural astronomers these days are interested not only the nature of astronomical observations but the context in which they were made and what they tell us about that context. Nonetheless, we do have to be cautious of the way our terminology is more widely perceived, the case study of La Horca del Inca in Bolivia (Pereira Quiroga, pp. 128-134) providing a case in point; and in that sense it is reasonable to concede that it is better not to refer to Taosi and Chankillo, mentioned above, as 'solar observatories'.

Issues such as terminology may be important but they are not, ultimately, the issues that really matter. The term 'interpretative archaeoastronomy' represents an attempt to focus attention on some of what I consider the more fundamental issues. I have used the term to suggest and reflect the fundamental shift that has taken place in the archaeological paradigm during the past thirty years towards what has become known as 'interpret[at]ive archaeology' (see, e.g., Thomas 2000) - something that has, in fact, helped to bring archaeoastronomy into the archaeological mainstream by stressing the importance of cognitive, rather than simply environmental, factors in framing human actions (Ruggles 2005). The evident need to reconcile, on the one hand, the specificity (in time and place) of many credible archaeological interpretations within this new paradigm and, on the other, the expectations of archaeological scientists seeking 'objective' readings of the material evidence, e.g. through statistical verification of repeated trends, to some extent parallels the problems faced by archaeoastronomers considering questions of how and why human constructions were situated in particular ways in their environment, 
something that (by considering alignments on horizon foresights) they had actually been doing years before archaeologists at large focused on such questions. Given this head start, has 'interpretative archaeoastronomy' made significant progress in the last three decades?

\section{Theoretical foundations}

\subsection{Principles and practice}

At Oxford 3 in 1990, Nick Saunders and I attempted to lay down some theoretical principles for archaeoastronomy by considering cultural perceptions of the natural environment and how people structure those perceptions in order to make sense of the world - the cosmos - they perceive and their place within it (Ruggles \& Saunders 1993b). Around that time and since, a range of different approaches has been developed, particularly by Iwaniszewki (e.g. 1991; 2001; this volume, pp. 30-37). The common quest is to establish solid foundations in anthropological and archaeological theory in order to formulate the most credible interpretations of evidence of the requisite kind. Meanwhile, historians and others bring their own perspectives to bear on this, an example being McCluskey's focus on the social construction of knowledge (e.g. McCluskey 2005). I do not wish to repeat these arguments here except to say that the theoretical foundations for investigations in cultural astronomy have improved considerably, and the process is ongoing.

The question is more, perhaps, how we apply these theoretical principles in practice. Certainly, this volume contains several excellent examples where the author is careful to establish an appropriate theoretical basis for the interpretations offered. Thus for example, Moyano (pp. 93-105) follows a psychological/phenomenological approach in which the human body is understood as a "filter, a tool and reference frame for the construction of sensory experience". It is an approach whose validity is already attested in the Andean world.

Many of the ethnographic case studies presented in this volume also reinforce the continuing need to deconstruct aspects of the Western viewpoint. Let me give an example of the subtleties this implies. Some readers might wonder why Faulhaber (pp. 58-64) concludes that "when the Ticuna [of Amazonia] talk today about the Woramacüri star in this specific configuration, we may correlate this celestial body with the planet Mars" rather than more simply "we can identify the Ticuna Woramacüri star as the planet Mars". She takes it as axiomatic that the a certain Ticuna 'star' may only be identified with (what we see as) a particular celestial body under a particular set of circumstances, just as among the Western Tobas of Argentina (Gómez, pp. 50-57) the Pleiades may represent a warrior leader in certain configurations, but carob at other times of year when the situation is different. In other words, there is a critical need to be aware of what Faulhaber terms "the limits of commensurability between different forms of knowledge, and in particular between indigenous perceptions and Western astronomy". This has implications for every indigenous 'star catalogue' and dictionary of indigenous astronomical terms and concepts.

The more general point here is that while 'we' (in the West) understand celestial bodies as entities in an external universe that exists, objectively, 'out there', for people in other human societies, both in the past and the indigenous present, everything they perceive typically forms part of an integrated whole in which the human mind, and human action, is embedded. Anthropologists have developed concepts such as 'lifeworld' and 'dwelling'/'being in the world' to help us to contemplate this (e.g. Ingold 2000). In this scheme of things, celestial bodies (for example) are "perceived as animate entities and their motions in the sky are described in terms of social relations.... Human societies 
often people their skies with supernaturals, ancestors or mythological heroes to whom they become related through family ties, mythological narratives, political alliances or power relationships. ... The celestial vault ... provides meaningful patterns suitable for conducting life on earth" (Iwaniszewski, this volume, p. 31). In other words, the sky functions as a cultural resource (Ruggles \& Saunders 1993b).

I shall give one further example relating to deconstruction, this time from the archaeological realm. Examples abound of attempts to draw a connection between spatial configurations on the ground - be it monumental architecture, the distribution of monuments, configurations of cupmarks, or patterns of deposition-and prominent configurations of stars. Although these examples include some notorious popular books, the idea also occurs in serious work by archaeologists and astronomers, including Therkorn (2004) and Tucker et al. (this volume, pp. 118-127). Quite apart from the methodological issues in drawing such conclusions - data selection (as regards both the monuments/cupmarks/ritual deposits and the stars), goodness of fit etc. - of which I do not wish to digress into a discussion here, there are also issues from the theoretical standpoint: native 'maps' do not generally represent entities or the distances between them in a manner that 'we' would consider 'literal'. Of course, there exist indigenous representations of the sky where certain asterisms are easily recognisable (see, e.g. Goto, this volume, pp. 317, 319), but generally speaking the significance attached to each of the entities rendered in so-called 'star charts' is culture- and context-dependent, so we cannot (for example) expect brighter stars to be depicted as bigger monuments or larger cupules, nor that the distances between them should reflect the actual angular distances in the sky at all accurately. Native 'star charts' - such as the Pawnee buckskin star chart discussed by Chamberlain (1982: 185-205), aspects of whose meaning were divulged by indigenous informants - demonstrate this clearly. Neither were such artefacts intended as "renditions of the sky" so much as devices that could capture star powers for various social purposes (ibid.: 193).

A major concern with the sort of analysis that seeks 'literal' (in the Western sense) representations of constellations in the layout of monuments or cupules is the apparent lack of cultural precedents. Broader syntheses of (what we might call) 'astronomical mapping' in different cultural contexts could be helpful here: a good example is Pankenier's (this volume, pp. 298-307) analysis of early Chinese buildings and landscapes mimicking the layout of the skies, and in particular the layout of early imperial capitals, arranged so as to accentuate the cosmological identification of the imperial centre with the celestial pole and circumpolar 'skyscape'. In other words, there may be value in drawing together work from far corners of the interdiscipline so as to provide insights into the possible circumstances and motives for, as well as the material results of, such behaviour. But again it is important to stress, as Pankenier does, that 'mapping' may be a misleading term: such layouts were not renditions of the heavens in the modern sense but rather (at least, in the Chinese case) a way of alluding to an elite's cosmological right to power and control.

\subsection{Building bridges}

It is one thing to be aware of such issues, but if we seek to 'bridge the gap' then we must move on from simply being a group of Western anthropologists 'looking out'. Here we can learn from the transformation of ethnology, which originally developed as the study of 'otherness' (López, this volume, pp. 41-42). A corollary of this transformation is that we should not ignore conceptions of the skies within modern Western culture itself (cf. Campion 2008: 110), which includes conceptions outside the scientific realm (i.e. popular beliefs). The special conference session on the 2012 phenomenon (this volume, pp. 178-254) 
addresses this in a novel way by pulling together studies of Mesoamerican and modern conceptions. But it is perhaps López who advances potential 'bridge-building' furthest, in the course of his examination of contemporary modes of discourse about astronomi$\mathrm{cal} /$ cosmological knowledge among the aboriginal communities of the Argentinian Chaco in the context of their interaction with a changing modern world (pp. 74-83). Reading this account of how relations between indigenous and 'Western' groups can play out in practice, three points emerge very clearly:

- Processes of development and change would evidently have affected indigenous astronomies/cosmologies continually before the arrival of the Europeans, just as they have since and do today. In this sense, attempts to help 'preserve' indigenous world-views (as 'intangible heritage' - see Cotte \& Ruggles 2010a) may be misguided; it is how they interact with modern world-views while keeping their identity that really matters.

- Things cosmological are intimately connected with things political. A prominent example is the Campo del Cielo crater field with its meteorites, a symbol of indigenous relationships to the landscape that is being cited in support of land claims.

- Perceived 'criteria of legitimacy' - used by key players within the indigenous community to uphold the indigenous world-view as relevant and important (e.g. in pursuit of political ends) - may well include reference to (what we would see as) a distorted view of 'white science' or to ideas that we would categorise as 'New Age' (see also Ruggles 2010), as well as to contemporary religious beliefs.

Recognizing complexities such as these, and taking measures to deal with them, is surely a prerequisite if the process of 'building bridges' is to move forward significantly and productively. We have a long way to go here, but we have only just begun.

\subsection{Mini-discipline or service discipline?}

Before leaving the topic of theory I would like to strike a more controversial note.

My question is this: is archaeoastronomy/cultural astronomy theoretically sustainable in its own right? This might seem an odd question to ask in view of what has just been said. I am certainly not questioning the need for archaeoastronomical interpretations to be theoretically well founded. But is it necessary — or even right - to try to develop archaeoastronomy/cultural astronomy as a mini-discipline with a distinct theoretical basis of its own? There is a perfectly viable alternative that would be acceptable to many, which is that we should view it as a 'service discipline' - in other words, a set of methods, techniques and skills to be adopted by archaeologists, historians, anthropologists etc. when they find themselves confronted by issues relating to the sky that arise in the broader context of whatever other cultural issues they are investigating. An extreme view would be that, in so far as we need ethno- or archaeoastronomical specialists at all, we simply need a group of people with a particular set of skills relating to the collection, reduction and interpretation of cultural astronomical data ready (i) to impart elements of those skills to social scientists at large when they need them and/or (ii) to join those people and work together, applying their specialist skills, in tackling wider archaeological/historical/anthropological problems. Indeed, aren't the countless successful collaborations between people with archaeoastronomical field and data reduction skills (frequently astronomers by training) and mainstream archaeologists good examples of this very principle?

Playing devil's advocate, perhaps, I would argue as follows. It is evident, from any reasonable theoretical standpoint, that human perceptions and actions relating to the sky are intertwined with perceptions and actions relating to almost anything else, cutting across Western categorisations and taxa, in ways that are certainly culturally relative and often entirely context-specific (e.g. Ruggles \& Saunders 1993b). Thus it is 
meaningless to attempt to derive a theoretical basis for archaeoastronomy as such, since there is no sense in studying sky-related beliefs and practices in isolation. $\dagger$ In the last three decades we have certainly made significant strides towards constructing an 'anthropology of astronomy' (Platt 1991), but this has been done - and must surely be done - using a set of elements from wider anthropological/archaeological/historical theory, rather than operating under the delusion that archaeoastronomical theory can be placed on an academic pedestal of its own. On the other hand, it would also be a mistake to go so far as view archaeoastronomy (taken in the 'pure' sense, for the moment, to illustrate the point) as a branch of archaeological science, similar in some ways to archaeobotany, conchology etc., but different in that it primarily addresses questions about what was going on in our ancestors' minds rather than ones concerning their physical circumstances such as environment and diet. This would fly in the face of the fact that cultural astronomers have to deal with serious theoretical issues. The closest parallel is probably landscape archaeology, which encapsulates a theoretical concern with how people constructed and used the environments around them, but also encompasses a range of field techniques and methods (e.g. Ashmore and Knapp 1999; Chapman 2006).

How we view the nature and status of archaeoastronomy/cultural astronomy bears upon how we see ourselves, its practitioners. Few would disagree these days that the archaeoastronomer is a variety of archaeologist/anthropologist/historian focused upon a particular set of cultural questions. If we follow the extreme 'service-discipline' view, then the archaeoastronomer (again in the pure sense) becomes equivalent, say, to the pottery specialist who is consigned to writing a specialist appendix or two at the end of the full archaeological site report (a role in which many of us have found ourselves from time to time). In order to legitimately progress beyond this, the archaeoastronomer not only has to focus on broader cultural questions but also has to have sufficient genuine interest in these broader questions not to become demotivated if the data start to produce non-astronomical answers. (It is obvious how interpretative bias could be introduced otherwise, with a tendency not to work through and publish what are perceived as 'negative' results. $\ddagger$ ) It is scarcely surprising that Gary Urton, our honoured guest speaker, despite producing a seminal ethnoastronomical work thirty years ago (Urton 1981), has spent most of his career investigating other issues that only touch from time to time upon calendrics and astronomy. Likewise the present author has recently spent a very stimulating four years directing a survey project concerning Nasca geoglyphs where it became evident, in the very early stages, that astronomy played very little or no demonstrable part in the symbolism of the geoglyphs being studied. How many archaeoastronomers would retain their interest in such circumstances?

\subsection{Summary: the development of theory over thirty years}

We have clearly come a long way since Oxford I, where social theory was not on the agenda at all, and Iwaniszewski's first attempt to introduce the topic onto the Oxford agenda at Oxford II (Iwaniszewski 1989). Explorations of theoretical issues are now commonplace at most conferences concerning cultural astronomy. As to the application of

$\dagger$ I have argued (Ruggles 2000a) that since we can reconstruct, with extraordinary accuracy, the configurations of the (regular) heavenly bodies observed by past peoples, so archaeoastronomy gives us a direct view of part of their perceived 'world', as opposed to other aspects of their visual environment about which our knowledge is generally far less specific. This gives archaeoastronomy a special significance for us a way to obtain better insights into broader questions, but does not imply that the sky was of singular importance to them.

$\ddagger$ Hoskin (2001: 13-15) has attempted to circumvent this problem by inventing the term 'archaeotopography' to describe the study of orientations without prejudice to the interpretation offered (astronomical or non-astronomical), but the term has not caught on. 
such principles in practice, over the last couple of decades it has become the norm even for those who consider purely archaeological evidence to interpret this in the context of broader social questions - examples abound in this book from those whose disciplinary roots are both in archaeology and astronomy. In this sense, the sort of discussion epitomised by the exchange between Kintigh and Aveni in 1992 (Kintigh 1992; Aveni 1992) is rightly consigned to the distant past. At the same time, it is vital to continue our attempts to establish secure theoretical foundations for archaeoastronomical interpretations, and important to seek common approaches - an argument advocated strongly by López (this volume, pp. 38-49) in striving to find ways forward for ethnoastronomy in South America, but which resonates through the whole of cultural astronomy around the world. While I believe it is wrong to consider the ultimate goal as being a theoretical basis for archaeoastronomy in its own right, the quest for a sturdy set of theoretical foundations that truly constitute an anthropology of astronomy remains no less relevant now than it did a quarter of a century ago.

\section{Methodological baselines}

\subsection{The starting point for methodological discourse}

Methodology is central to our endeavours as archaeoastronomers. Theoretical soundness is of little value if accompanied by a level of methodological weakness that undermines the scientific process of considering the actual evidence. To take a familiar, if hackneyed, example, interpretations of astronomically aligned architecture, however 'theoretically aware' and well contextualized, are valueless if they are based on a badly misleading selection of the material data. Of course, the theoretical advances in the meantime have made it clear to all in 2011, as was not the case back in 1981, that any perceived 'objectivity' is itself theory-laden, since in defining it we impose our own cultural baggage (e.g. Ruggles \& Saunders 1993b: 17-18; Iwaniszewski 2001: 2); but this does not in the least diminish the need for due attention to methodology.

Of course, this sort of argument harks back to Aveni's 'green' v. 'brown' divide, articulated almost 25 years ago to the day at Oxford II, but we have moved on. The days are long gone when significantly many archaeoastronomers spent their time investigating alignments largely unaware of, or at least unconcerned by, the broader archaeological/anthropological context and the wider social questions engendered by that context. This is not to say that those of us working at the prehistoric end of things should not ask ourselves from time to time to what extent we still furtively follow Aveni's 'Thom paradigm' (Aveni 1988), applying a recipe book of astronomical targets - if the sun doesn't fit, then try the moon, and if that doesn't fit then try the stars - while merely paying lip-service to the broader context. But I would go so far as to say that archaeoastronomers back in the 1980s led the way for archaeologists in considering how places and monuments related to the broader landscape (and skyscape). Landscape archaeologists today are still struggling to reconcile the theoretical richness of interpretative approaches such as Tilley's (1994) with the apparent subjectivity of their application in practice to the prehistoric record (e.g. Fleming 2005; 2006). Our 'green' v. 'brown' arguments in many ways paralleled these and successfully found ways forward.

The basic position, as I see it, is best expressed using a concrete example. An ideal one is provided by the so-called E-group structures, a distinctive arrangement of pyramid, plaza and platform found at several Mayan complexes concentrated in the Petén, Guatemala (Aveni \& Hartung 1989; Aylesworth 2004). In brief: $†$

$\dagger$ Here I am radically simplifying the picture so as to make the basic point. For a much fuller discussion of the E-group structures and possible interpretations see, e.g., Aveni \& Hartung 1989; Aveni 2001: 288-293; Aveni et al. 2003; Aylesworth 2004 and references therein. 
1) The type-site at Uaxactún contains solstitial and equinoctial sunrise alignments, recognised since the $1920 \mathrm{~s}$.

2) Of some 50 such sites, despite their similar layout, at most a very few repeat these alignments.

3) Archaeological evidence shows that the Uaxactún site itself was modified so that the actual alignments became dysfunctional at later stages.

A 1980s-style 'purely statistical' approach would clearly dismiss the Uaxactun alignments as fortuitous. However a suggestion backed up by a good deal of circumstantial evidence arising from the archaeological context is that the other structures were "nonfunctional copies', perceived as incorporating solar symbolism, even if in the majority of cases this did not need to be reaffirmed by actual observations. At Uaxacún itself this became the case at later periods.

As I say, I am ignoring a variety of other interpretations in order to make a more fundamental point, which is this. How viable is the idea that the E-group structures were all perceived as solar-related, but where the great majority were 'non-functional copies'? Theoretically speaking, it is much more credible than the idea that all the sites should have been built as functioning observing devices (which is too close to the modern concept of observatories and astronomers), and the evidence at Uaxactún itself can be argued in its support. But it opens the way to a totally subjective reading of the evidence, in which those sites that have the requisite alignments can be interpreted as those with functioning observing devices, while the others can be interpreted as those that never needed them.

There is clearly a balance to be sought between theory and method - or, to be more precise, between the credibility of the interpretation offered (in terms of broader social theory) and the strength of the evidence produced in its support (which is where the field methodology is crucial). There is also a need to assess how we balance different types of evidence, for example weighing the strength of repeated trends against broader contextual evidence that supports more specific 'one-off' interpretations. Such issues have faced archaeologists generally during the transformation of their discipline due to interpretative archaeology: this transformation, while forcing archaeologists to face up to the importance of historical context and specificity, and of the cognitive/symbolic element in shaping human action, also introduced a subjectivity that aggravated those who, if not countenancing a return to the 'hypothesis testing' of the 1970s, nonetheless felt that rigorous/systematic methods must retain an essential place in their fieldwork.

This balance, it seems to me, is the starting point for methodological discourse - at least, at the archaeological end of things where we are considering the spatial disposition of material remains - and has been for some 20 years.

\subsection{Data-driven and onward}

Some who approach this issue from the social science end of things might well feel that there is no place in archaeoastronomy for the sort of 'data-driven' approach taken by Hoskin in analysing the principal orientations of over 3000 later prehistoric tombs and temples in western mediterranean Europe (Hoskin 2001). $\dagger$ Yet the success of Hoskin's work is undeniable in persuading many European archaeologists that orientation was indeed an important design consideration and that it most cases it had a broad connection

$\dagger$ Hoskin was aware of the archaeological context, but the project was conceived as one of 'pure' data collection and the limits of interpretation were to identify 'orientation signatures' of local groups of monuments and to reach broad conclusions about their possible connection to astronomical bodies and the diffusion of ideas and practices. 
with the sun, moon or stars. The more recent work of Belmonte and his colleagues in their surveys of some 330 alignments at Egyptian temples and pyramids (Belmonte et al. 2008; Belmonte \& Shaltout 2009) also provides clear testimony to the success and value of such an approach.

In some ways, we are fortunate that such an approach bears fruit among the megalithic monuments of mediterranean Europe; it does not work so well among, say, Polynesian temples (cf. Edwards, this volume, pp. 275-281) where we need ethnohistory along with the archaeology to help reveal solar, stellar, cardinal and topographical associations that differ according to the purpose of the temple (Kirch 2004; Ruggles 2007). Likewise, among Classical Greek temples, it is only by combining evidence from archaeoastronomy and historical literature that we can begin to reconstruct aspects of ancient Greek religious practices and their relationship to particular constellations, including stellar alignments at temples particular to certain goddess cults (Boutsikas \& Ruggles 2011; Boutsikas \& Hannah, this volume, pp. 342-348).

Yet even when dealing with prehistoric constructions such as the European megaliths, where we must rely upon archaeological data alone, there is potential to contextualise the existing studies further. There are plenty of examples in Britain and Ireland where the wider archaeological context enhances the interpretation (Ruggles 1999), including Stonehenge (Ruggles 2006). One possibility is to focus on the specific landscape situation of monuments in a certain orientation group, as was done in the 1980s on the Scottish island of Mull (Ruggles 1999: 112-124). Another is to include the vertical dimension, an example being Saletta's (this volume, pp. 364-373) considerations of putative light-andshadow hierophanies at the Arles-Fontvieille passage graves in southern France. Zotti \& Neubauer's (pp. 349-356) computer-generated visualisations of Neolithic circular ditch systems (Kreisgrabenanlagen) in Austria combine elements of both these approaches in showing how a consideration of the height of constructed features may sway the hypothesis in favour of, say, deliberate solstitial orientation; similar results have been obtained at the 'great cairn' containing 11 passage tombs at Barnenez on the northern coast of France (Ruggles \& Rousseau n.d.). Some papers in this volume contextualise conventional 'alignment studies' in innovative ways - for example, González-García \& Costa-Ferrer (pp. 374-381), working in western Spain, propose a methodology with the potential to make useful deductions about social and ideological change from very small orientation data sets by comparing data across long time periods in the same region-while others use more conventional approaches, such as Munro \& Malville's (pp. 255-264) contextualisation of changing patterns of orientation at Chaco, New Mexico, using broader archaeological and cultural evidence.

\subsection{Interpreting 'one-offs'}

Those who, on the other hand, approach the question of balancing theory and method from the 'hard science' end of things might well agree with Belmonte's (2010) sentiment "testis unus, testis nullus", in other words, unique interpretations for unique types of monument are scientifically untestable. However, it would clearly be ridiculous to throw out unconditionally interpretations of unique monuments based on contextual evidence of the type commonly encountered and considered by anthropologists, archaeologists and historians. (Indeed, everything is unique at some level.) Belmonte tellingly concludes "we must be very cautious of risking [overly] adventurous conclusions" (ibid.). This, of course, begs the question of how we make the assessment of whether a conclusion is reasonable or not in view of the evidence available. Clearly in some cases the interpretations offered 
are so far-fetched as to be beyond serious consideration, $\nmid$ but generally one must carefully weigh up the various types of evidence in order to come up with the most viable, as well as the most theoretically sound, interpretations. Nowhere is this more critical than at the sites that, for one reason or another, have become emblematic of archaeoastronomy both among our academic peers and the public at large: as Schaefer (2006a) argued at Oxford VII, we need credible exemplars.

Methodological disputes concerning key sites in archaeoastronomy are legion, one of the most recent being the exchange between Schaefer (2006a; 2006b) and Aveni (2006a; 2006b) at Oxford VII. In essence, Schaefer's case was that three of the most iconic archaeoastronomical sites in North America-Bighorn medicine wheel and Cahokia in the USA, and the Caracol at Chichen Itza in Mexico - are actually unproven to have astronomical meaning. In support of this view he provided a detailed refutation both of the statistical evidence and the corroborating evidence, and concluded that there is no proof that the claimed alignments were intentional. Aveni strongly contested this in the case of the Caracol, giving his own reading of the contextual evidence and arguing for example that some alignments that Schaefer had pointed out as being blocked (which Aveni did not dispute) may not have been 'functional' but symbolic. Actually, the two proponents were arguing about how 'formal' methods should be played off against 'informed' methods, to borrow a categorisation suggested in rock-art studies (Taçon \& Chippindale 1998). Rather than attempting to paraphrase the debate further (as it continued, it descended rather less productively into accusations of ethnocentrism etc.), it is worth focusing on some of the points of agreement:

- A word of ethnography is worth a thousand alignments.

- Replication is important in deciding whether an alignment was intentional or not.

- In interpreting their purpose and meaning, alignments cannot be divorced from their cultural context.

- (At the Caracol) Aveni will never prove intentionality any more than Schaefer will ever disprove it.

Given the rise to prominence of Chankillo following the widespread publicity it received in 2007 as 'America's oldest solar observatory', it is hardly surprising that it has been the focus of a similar methodological debate at Oxford IX, reflected in the two papers in this volume by Ghezzi \& Ruggles (pp. 144-153) and Malville (pp. 154-161). Ghezzi and I argue that the global significance of this site derives from the presence of a string of foresights (the thirteen towers) spanning the entire sunrise arc as viewed from an evident observing point to the west and a plausible observing point to the east - a very different prospect from the single alignments much more characteristic of the evidence available to archaeoastronomers. Malville, on the other hand, argues that this set of alignments is fortuitous and that the towers had a more important function as the site of ritual processions over a series of 'symbolic mountains'.

I shall not abuse editor's privilege in order to continue the argument here (this will be done in a separate publication), but again it is worth drawing out significant points of agreement:

- Chankillo was not an observatory if that is taken to mean a place exclusively dedicated to astronomical observations.

$\dagger$ It is unfortunate for the reputation of cultural astronomy that such work continues on occasion to reach peer-reviewed publications. A recent example is Henriksson's (2010) interpretation of Swedish rock carvings as literal depictions of eclipses, continuing to propagate an idea that lacks credibility on a number of levels (Lindström \& Roslund 2000; Ruggles 2005: 412-414; see also (e.g.) Whitley 2008: 89 on conflating depiction with meaning). 
- The overall plan of the various plazas and buildings surrounding the towers is constructed on a roughly solstitial axis.

- Chankillo had significance in terms of solar-related cults and rituals.

- There may well also have been elements of lunar-based ritual.

It is also worth emphasizing some of the main methodological points at issue:

- The June solstice sun does not rise behind Tower 1 as seen from the western observing point, but at a hill junction (as newly discovered and reported in this volume) just to the left. Does this fatally weaken the 'arc of sunrise' argument or can we put significant weight on contextual arguments why this may have been deliberate?

- The gaps between the towers were more or less equally spaced, rather than closer together at the ends, so that they did not mark off regular time intervals throughout the year. Does this fatally weaken the idea that the towers could have been used as a calendar in the sense that they provide a means to identify every day in the year by observing the position of sunrise in relation to the various towers and the gaps between them?

- The more damaged eastern observing point does not stand out as special location in the same way as does the western observing point, with its doorless opening and concentration of cult offerings. Excavations have, however, revealed a small isolated building at the requisite spot. How strongly should we countenance the possibility that the towers were used to sight upon sunsets as well?

There is certainly more to the discussion, particularly involving how we factor in various types of circumstantial evidence from the broader context, but it is clear that these three points raise broadly familiar issues relating to selection methodology - in particular, how we play off the desire for a clean and simple explanation against more messy contextual arguments (typically, such arguments are better grounded theoretically - see previous section) that permit more flexibility in interpretation but also more subjectivity in reading the data. Clearly the health and value of any debate about interpretation and methodology in a case such as this is ultimately to be measured in the quality of the shared consensus that it eventually produces. The fundamental issue is that we need generally applicable procedures for reaching that consensus.

\subsection{Finding the middle ground}

What progress have we actually made in the last few years in assessing the sorts of assertions and counter-assertions produced, for example, at Chankillo? I have been arguing for many years the need for more rigorous methodologies for combining different types of evidence (e.g. Ruggles \& Saunders 1993b: 16-21) and have made various attempts to explore this issue (e.g. Ruggles 1994; 2000b). Others disagree; most notably Aveni, who at Oxford VII criticised this approach in that it

"... presupposes that tools and methods from the physical sciences can readily be adapted to the social sciences. They cannot." (Aveni 2006a: 65).

While I have long since abandoned my insistence of thirty years ago upon a statistical objectivity that we all now agree to be undesirable and unobtainable, I stand by the need for scientific rigour (Ruggles 1984; cf. Aveni 2008: 9). The fallacy in Aveni's argument is actually exposed a little later in the Oxford VII Proceedings, in an excellent paper by Whitley (2008). Whitley, whose research field is rock art, begins by asking the question why, as he perceives it, rock-art studies have "emerged out of the shadows" within archaeology in the USA while archaeoastronomy "continues to stand out on the edge". He suggests that this is because scientific method has become carefully adhered to in 
rock-art studies, while "methodological errors remain one of the central characteristics, and thus key weaknesses, of many archaeoastronomical studies" (ibid.: 86).

Whitley, unlike Aveni, is speaking here of a post-positivist scientific method based on inferential reasoning, where

"interpretative hypotheses (e.g. about the origin and meaning of rock art ... are as amenable to scientific testing as physical hypotheses (e.g. about the nature of the universe). The old belief that some subjects are intrinsically 'more scientific' than others is a ... leftover from confused Enlightenment-era notions." (ibid.: 87).

The basis for selecting a hypothesis over its competitors is inference, not testing, and the strongest support for a given hypothesis comes from multiple lines of evidence leading to the same conclusion (convergent methodologies) rather than a single logical chain of inference. Two further key points emerge from Whitley's discussion:

1) Systematic (rather than 'anecdotal') data collection is crucial.

2) The process is slow and painstaking.

The point I wish to emphasize here is that scientific/methodological rigour is an essential part of the way in which archaeoastronomers must tackle wider issues of relevance in archaeology (and equally well in anthropology or history), not something that runs counter to that goal.

\subsection{Ways forward}

Arguments over data selection and methodology are as old as archaeoastronomy itself, but they have become even more crucial in these days of increased theoretical awareness. Ultimately, only the principle that all our hypotheses are open to scientific scrutiny can enable us to develop robust procedures and methods for integrating the diverse strands of evidence with which the cultural astronomer has to deal and for inferring the most appropriate interpretations.

In the last thirty years we have not improved our methodologies as might have been hoped. One reason may be that we tend to keep replaying the same arguments, an example being MacKie's (2009) continuing insistence on the existence of 'fundamental flaws' in the current author's critiques of Thom's 'megalithic observatories', despite the fact that these criticisms have been comprehensively addressed (for details see Ruggles \& Barclay 2000: 69-70). Moving on involves not only a healthy level of debate and discussion over methodology and interpretation when it comes to new discoveries, as we have at Oxford IX over Chankillo, but ensuring that we continue to review our methods generally and to break new boundaries.

Of course, we must constantly re-examine more fundamental methodological procedures for extracting data and forming viable interpretations in context. Certain questions like the basic one of 'fair' data selection remain as relevant as ever; to take an example at random from the current volume, we need to be confident that statements like "The fact that 15 of Raivavae's marae are oriented towards the rising point of Aldebaran, and 10 of them towards the setting point of Antares, cannot be coincidental" (Edwards, p. 277) are not only borne out statistically but also supported by clear evidence of the 'fairness' of the sample. Not only is this vital for the credibility of cultural astronomy itself (cf. Schaefer 2006a); it is also crucially important in determining the credibility of ancient sites connected with astronomy and hence their importance as astronomical heritage (Cotte \& Ruggles 2010b: 270-271; cf. Pereira Quiroga, pp. 128-134).

Thoughts about general advances in methodology should be in the background in many more of our projects - what does each of our case studies offer by way of potential methodological improvement? For example, as López (p. 82) points out, the study of the 
dynamics of change of indigenous cosmologies in the contemporary world can help us improve methodological tools for comprehending the relationship of such cosmologies to social and political change, and particularly struggles for power and leadership, in the past as well as the present. On the archaeological side, it is the intention in my own work that each main ongoing research project should address key methodological issues as well as wider cultural issues. Thus for example:

- In prehistoric Europe (as already mentioned), the question is how we best go about adding contextual layers to the 'data-driven' interpretations supplied by Hoskin and his colleagues.

- In the Stonehenge area in particular (see Ruggles 2006), the issue is how we weigh the evidence in cases mid-way between those where similar monuments exist in sufficient numbers for evidence from repeated trends to be strong, and solely contextual interpretations of unique sites (cf. Ruggles 2000b). Here we have just a handful of sites with repeated solstitial alignments.

- In Hawai'i (see Ruggles 2007), a central question is how we weigh the 'informed' evidence against the 'formal' archaeoastronomical evidence (alignments etc.) in a context where the former consists merely of a few precious fragments of 'oral history', together with accounts recorded since European occupation and present-day knowledge, both much acculturated.

- How strongly can we weigh the type of alignment evidence, so far found only at Chankillo and Taosi, that seems to indicate an all-year-round solar observation device? How many other threads of evidence, both formal and informed, converge upon the same conclusion as opposed to competing interpretations?

Developing robust methodologies for weighing together the different types of evidence faced by the archaeoastronomer in different situations is far from easy. Some aspects of the inferential process may be quantifiable, particularly using a Bayesian formalism, as I have suggested on several occasions (e.g. Ruggles 1994). At Oxford VI, I tried to develop a more rigorous approach to weighing together types of data commonly encountered by the archaeoastronomer that can be characterised as 'general' and 'specific' (Ruggles 2000b). But we have a long way to go.

Many excellent papers at this conference touch upon important themes that raise distinctive sets of methodological issues. One such theme is 'natural alignments' - (what we would see as) accidents of nature that became culturally significant by making a place seem special or sacred (cf. Belmonte \& Barba, pp. 135-143). Another somewhat related theme is that of astronomical hierophanies in architecture that were unintentional initially but subsequently discovered and duly appropriated or elaborated - either in the past, as may have happened for example in some medieval churches (cf. McCluskey 2010) or in modern times, as may well be the case at the pyramid of Kukulcan at Chichen Itza (Carlson 1999). We are forced to recognise this as a possibility wherever one-off modern hierophanies, however spectacular, are (as yet) unattested by any form of independent cultural evidence (see, e.g., Komonjinda, pp. 325-330) but we can also view the possibility positively, as providing useful insights into more general processes of changing significance and meaning. Another important theme that has distinctive methodological implications is the development of astronomical concepts and practices in island environments (Edwards, pp. 275-281; Goto, pp. 315-324); another (related) theme is suggested by Renshaw's (pp. 308-314) study of Japanese acculturation, both historically and in modern times, of astronomical concepts and practices from other cultures into a world-view that remains quintessentially Japanese. The list could be extended almost indefinitely; indeed, the geographical organisation of the papers that 
follows reflects the SOC's decision that nearly all papers addressed multiple themes, so any attempt at a thematic organisation of the conference programme was meaningless.

It is not simply desirable to identify rigorous and robust methodologies for weighing together the different types of data with which the cultural astronomer is faced in different sitations. Doing so forms a vital part of the process of inferring the best hypothesis to explain the data in any given instance. This remains at once the most challenging and the most pressing issue facing our 'interdiscipline' in the future.

\section{Conclusion}

What best defines and characterises archaeoastronomy/cultural astronomy today? Moyano (p. 96, paraphrasing Iwaniszewski 2009) captures the essence when he says that it "studies the mechanisms by which people come to understand astronomical phenomena. It analyzes their systems of conceptualization and representation and correlates social connections, social processes and sets of ideas about social life".

The sky is of universal importance. Cultural perceptions of the sky are vital in fulfilling humankind's most basic need to comprehend the universe it inhabits, both from a modern scientific perspective and from countless other cultural standpoints, extending right back into early prehistory. They form a fundamental aspect of people's conceptions of their own cultural identity. Developing an understanding of these perceptions is a crucial component of Western anthropologists', archaeologists' and historians' efforts to comprehend human conceptions and actions both in the past and in the present.

Why is cultural astronomy relevant to modern astronomers? The broad answer is that understanding the human context of what has often been referred to as 'the oldest science' extends well beyond the history of modern, Western scientific astronomy. It must include a wider 'anthropology of astronomy' that reveals the extraordinary diversity of ways in which people have comprehended what they perceived in the skies, and exploited this knowledge for cultural ends. The 'building bridges' of the conference title relates to broader cultural sympathies for (modern) astronomy, particularly in the developing world. I have argued elsewhere (Ruggles 2010) that there is a range of positive benefits for progress in scientific astronomy to be derived from the mutual awareness and comprehension of other cultural world-views whose goals - in common with those of modern science - are to make sense of the cosmos within which people live. A prerequisite is to recognise that from an anthropological point of view, the whole concept of a 'ladder of progress' in astronomical discovery is anathema (cf. Aveni 2001: 7), since it implicitly downgrades other cultural perspectives, such as the many indigenous cosmologies that still exist in the modern world. One of the most obvious potential benefits of striving to understand, and ultimately to respect, non-Western frameworks of thought - of using astronomy as a focus for 'building bridges between cultures' - derives from common attitudes towards the heritage of astronomy, both cultural-including some of our most emblematic ancient and historical astronomical sites - and natural, namely the preservation of dark skies.

In the last thirty years most archaeoastronomers have come to realise that it is essential to strengthen the theoretical basis for archaeoastronomy by appropriating relevant theoretical concepts from (particularly) anthropology and striving to identify explicitly the philosophical paradigms within which we are working. Such efforts continue at an increasing pace. But, as I have argued in this paper, the need for our hypotheses to be solidly grounded in social theory is no excuse for avoiding the need to be scientifically rigorous in assessing them against the actual evidence. 


\section{References}

Ashmore, W. \& Knapp, A. B. (eds) 1999, Archaeologies of Landscape: Contemporary Perspectives, Blackwell, Oxford.

Aveni, A. F. (ed.) 1982, Archaeoastronomy in the New World, Cambridge University Press, Cambridge.

Aveni, A. F. 1988, The Thom paradigm in the Americas: the case of the cross-circle designs. In C. L. N. Ruggles (ed.), Records in Stone: Papers in Memory of Alexander Thom, Cambridge University Press, Cambridge, pp. 442-472.

Aveni, A. F. (ed.) 1989, World Archaeoastronomy, Cambridge University Press, Cambridge.

Aveni, A. F. 1992, Nobody asked, but I couldn't resist: a response to Keith Kintigh on archaeoastronomy and archaeology. Archaeoastronomy and Ethnoastronomy News 6, 1.

Aveni, A. F. 2001, Skywatchers, University of Texas Press, Austin.

Aveni, A. F. 2006a, Evidence and intentionality: on method in archaeoastronomy. In T. W. Bostwick \& B. Bates (eds) 2006, Viewing the Sky through Past and Present Cultures, Pueblo Grande Museum Anthropological Papers no. 15, City of Phoenix, Phoenix, pp. 57-70.

Aveni, A. F. 2006b, Schaefer's rigid ethnocentric criteria. In T. W. Bostwick \& B. Bates (eds) 2006, Viewing the Sky through Past and Present Cultures, Pueblo Grande Museum Anthropological Papers no. 15, City of Phoenix, Phoenix, pp. 79-83.

Aveni, A. F. 2008, The unwritten record. In A. F. Aveni (ed.), Foundations of New World Cultural Astronomy. A Reader with Commentary, University Press of Colorado, Boulder, pp. 1-11.

Aveni, A. F., Dowd, A. S., \& Vining, B. 2003, Maya calendar reform? Evidence from orientations of specialized architectural assemblages. Latin American Antiquity 14, 159-178.

Aveni, A. F. \& Hartung, H. 1989, Uaxactun, Guatemala, Group E and similar assemblages: an archaeoastronomical reconsideration. In A. F. Aveni (ed.), World Archaeoastronomy, Cambridge University Press, Cambridge, pp. 441-461.

Aylesworth, G. R. 2004, Astronomical interpretations of ancient Maya E-group architectural complexes. Archaeoastronomy. The Journal of Astronomy in Culture 18, 34-66.

Belmonte, J. A. 2010, Finding our place in the cosmos: the role of astronomy in ancient cultures. Journal of Cosmology 9, 2052-2062.

Belmonte, J. A. \& Shaltout, M. (eds) 2009, In Search of Cosmic Order: Selected Essays on Egyptian Archaeoastronomy, American University in Cairo Press, Cairo.

Belmonte, J. A., Shaltout, M., \& Fekri, M. 2008, On the orientation of ancient Egyptian temples: (4) Epilogue in Serabit el Khadim and overview. Journal for the History of Astronomy 39, $148-211$.

Bostwick, T. W. \& Bates, B. (eds) 2006, Viewing the Sky through Past and Present Cultures, Pueblo Grande Museum Anthropological Papers no. 15, City of Phoenix, Phoenix.

Boutsikas, E. \& Ruggles, C. L. N. 2011, Temples, stars, and ritual landscapes: the potential for archaeoastronomy in ancient Greece. American Journal of Archaeology, 115(1), 55-68.

Campion, N. 2008, Teaching cultural astronomy: on the development and evolution of the syllabus at Bath Spa University and the University of Wales, Lampeter. In J. C. Holbrook, R. T. Medupe \& J. O. Urama (eds), African Cultural Astronomy. Current Archaeoastronomy and Ethnoastronomy Research in Africa, Springer, New York, pp. 109-119.

Carlson, J. B. 1999, Pilgrimage and the equinox 'serpent of light and shadow' phenomenon at the Castillo, Chichén Itzá, Yucatán. Archaeoastronomy. The Journal of Astronomy in Culture 14(1), 136-152.

Chamberlain, V. D. 1982, When Stars Came Down to Earth. Cosmology of the Skidi Pawnee Indians of North America, Ballena/Center for Archaeoastronomy, Los Altos/College Park.

Chapman, H. 2006, Landscape Archaeology and GIS, Tempus, Stroud.

Cotte, M. \& Ruggles, C. L. N. 2010a, Introduction. In C. L. N. Ruggles \& M. Cotte (eds), Heritage Sites of Astronomy and Archaeoastronomy in the Context of the UNESCO World Heritage Convention. A Thematic Study, ICOMOS-IAU, Paris, pp. 1-12.

Cotte, M. \& Ruggles, C. L. N. 2010b, Conclusion. Astronomical heritage in the context of the UNESCO World Heritage Convention: developing a professional and rational approach. In C. L. N. Ruggles \& M. Cotte (eds), Heritage Sites of Astronomy and Archaeoastronomy in the Context of the UNESCO World Heritage Convention. A Thematic Study, ICOMOSIAU, Paris, pp. 260-272. 
Esteban, C. \& Belmonte, J. A. (eds) 2000a, Oxford VI and SEAC 99: Astronomy and Cultural Diversity, Organismo Autónomo de Museos del Cabildo de Tenerife, La Laguna.

Esteban, C. \& Belmonte, J. A. (eds) 2000b, Archaeoastronomy. The Journal of Astronomy in Culture 15, 3-177.

Fleming, A. 2005, Megaliths and post-modernism: the case of Wales. Antiquity 79, 921-932.

Fleming, A. 2006, Post-processual landscape archaeology: a critique. Cambridge Archaeological Journal 16(3), 267-280.

Fountain, J. W. \& Sinclair, R. M. (eds) 2005, Current Studies in Archaeoastronomy: Conversations across Time and Space, Carolina Academic Press, Durham NC.

Ghezzi, I. \& Ruggles, C. L. N. 2007, Chankillo: a 2300-year-old solar observatory in coastal Peru. Science 315, 1239-1243.

Heggie, D. C. (ed.) 1982, Archaeoastronomy in the Old World, Cambridge University Press, Cambridge.

Henriksson, G. 2010, Einstein's theory of relativity confirmed by ancient solar eclipses. Journal of Cosmology 9, 2137-2146.

Hoskin, M. A. 2001, Tombs, Temples and their Orientations, Ocarina Books, Bognor Regis.

Ingold, T. 2000, The Perception of the Environment. Essays in Livelihood, Dwelling and Skill, Routledge, London \& New York.

Iwaniszewski, S. 1989, Exploring some anthropological theoretical foundations for archaeoastronomy. In A. F. Aveni (ed.), World Archaeoastronomy, Cambridge University Press, Cambridge, pp. 27-37.

Iwaniszewski, S. 1991, Astronomy as a cultural system. Interdisciplinarni Izsledwaniya 17, 282 288.

Iwaniszewski, S. 2001, Time and space in social systems - further issues for theoretical archaeoastronomy. In C. L. N. Ruggles, F. Prendergast \& T. P. Ray (eds), Astronomy, Cosmology and Landscape, Ocarina Books, Bognor Regis, pp. 1-7.

Iwaniszewski, S. 2009, Por una astronomía cultural renovada. Complutum 20, 23-37.

Kintigh, K. W. 1992, I wasn't going to say anything, but since you asked: archaeoastronomy and archaeology. Archaeoastronomy and Ethnoastronomy News 5, 1 \& 4.

Kirch, P. V. 2004, Temple sites in Kahikinui, Maui, Hawaiian Islands: their orientations decoded. Antiquity 78, 102-114.

Lindström, J. \& Roslund, C. 2000, Arkeoastronomi och Göran Henrikssons nonsensforskning. Folkvett 3-4, 7-30 (http://www.vof.se/folkvett/20003-4goran-henrikssonsnonsensforskning) [in Swedish].

McCluskey, S. C. 2005, Different astronomies, different cultures and the question of cultural relativism. In J. W. Fountain \& R. M. Sinclair (eds), Current Studies in Archaeoastronomy: Conversations across Time and Space, Carolina Academic Press, Durham NC, pp. 69-79.

McCluskey, S. C. 2010, Medieval astronomy in Europe. In C. L. N. Ruggles \& M. Cotte (eds), Heritage Sites of Astronomy and Archaeoastronomy in the Context of the UNESCO World Heritage Convention. A Thematic Study, ICOMOS-IAU, Paris, pp. 169-187.

MacKie, E. W. 2009, The prehistoric solar calendar: an out-of-fashion idea revisited with new evidence. Time and Mind 2(1), 9-46.

Malville, J. M. \& Holbrook, J. (eds) 2010, Archaeoastronomy: Cosmology of Ancient Cultures. Journal of Cosmology 9, 2030-2244 (http://JournalofCosmology.com/Contents9.html).

Platt, T. 1991, The anthropology of astronomy [essay review of Aveni 1989]. Archaeoastronomy no. 16 (supplement to Journal for the History of Astronomy 22), S76-S83.

Ruggles, C. L. N. 1984, Megalithic astronomy: the last five years. Vistas in Astronomy 27, 231-289.

Ruggles, C. L. N. (ed.) 1993, Archaeoastronomy in the 1990s, Group D Publications, Loughborough.

Ruggles, C. L. N. 1994, The meeting of the methodological worlds? Towards the integration of different discipline-based approaches to the study of cultural astronomy. In S. Iwaniszewski, A. Lebeuf, A. Wierciński and M. Ziółkowski (eds), Time and Astronomy at the Meeting of Two Worlds, Centro de Estudios Latinoamericanos, Uniwersytet Warszawski, Warsaw, pp. $497-515$.

Ruggles, C. L. N. 1999, Astronomy in Prehistoric Britain and Ireland, Yale University Press, New Haven \& London. 
Ruggles, C. L. N. 2000a, Ancient astronomies-ancient worlds. Archaeoastronomy no. 25 (supplement to Journal for the History of Astronomy 31), S65-S76.

Ruggles, C. L. N. 2000b, The general and the specific: dealing with cultural diversity. Archaeoastronomy. The Journal of Astronomy in Culture 15, 151-177.

Ruggles, C. L. N. 2005, Archaeoastronomy. In C. Renfrew \& P. Bahn (eds), Archaeology: the Key Concepts, Routledge, Abingdon.

Ruggles, C. L. N. 2006, Interpreting solstitial alignments in Late Neolithic Wessex. Archaeoastronomy. The Journal of Astronomy in Culture 20, 1-27.

Ruggles, C. L. N. 2007, Cosmology, calendar, and temple orientations in ancient Hawai'i. In C. L. N. Ruggles \& G. Urton (eds), Skywatching in the Ancient World. New Perspectives in Cultural Astronomy, University Press of Colorado, Boulder, pp. 287-329.

Ruggles, C. L. N. 2010, Indigenous astronomies and progress in modern astronomy. In R. P. Norris (ed.), Accelerating the Rate of Astronomical Discovery, SpS5, August 11-14 2009, Rio de Janeiro, Brazil. Proceedings of Science, PoS(sps5)029. http://pos.sissa.it/ archive/conferences/099/029/sps5_029.pdf.

Ruggles, C. L. N. \& Barclay, G. J. 2000, Cosmology, calendars and society in Neolithic Orkney: a rejoinder to Euan MacKie. Antiquity 74, 62-74.

Ruggles, C. L. N. \& Rousseau, A. n.d., Solstitial sunlight and the Great Cairn of Barnenez, Finistère. Publication in preparation.

Ruggles, C. L. N. \& Saunders, N. J. (eds) 1993a, Astronomies and Cultures, University Press of Colorado, Niwot.

Ruggles, C. L. N. \& Saunders, N. J. 1993b, The study of cultural astronomy. In C. L. N. Ruggles \& Saunders, N. J. (eds), Astronomies and Cultures, University Press of Colorado, Niwot, pp. 1-31.

Ruggles, C. L. N. \& Urton, G. 2007, Introduction. In C. L. N. Ruggles \& G. Urton, Skywatching in the Ancient World: New Perspectives in Cultural Astronomy, University Press of Colorado, Boulder, pp. 1-15.

Schaefer, B. E. 2006a, Case studies of three of the most famous archaeoastronomical alignments in North America. In T. W. Bostwick \& B. Bates (eds) 2006, Viewing the Sky through Past and Present Cultures, Pueblo Grande Museum Anthropological Papers no. 15, City of Phoenix, Phoenix, pp. 27-56.

Schaefer, B. E. 2006b, No astronomical alignments at the Caracol. In T. W. Bostwick \& B. Bates (eds) 2006, Viewing the Sky through Past and Present Cultures, Pueblo Grande Museum Anthropological Papers no. 15, City of Phoenix, Phoenix, pp. 71-77.

Taçon, P. S. C. \& Chippindale, C. 1998, An archaeology of rock-art through informed methods and formal methods. In C. Chippindale \& P. S. C. Taçon (eds), The Archaeology of Rock Art, Cambridge University Press, Cambridge, pp. 1-10.

Therkorn, L. L. 2004, Landscaping the Powers of Darkness and Light: 600 BC-350 AD Settlement Concerns of Noord-Holland in Wider Perspective. PhD thesis, University of Amsterdam, Amsterdam. http://dare uva.nl/document/120954.

Thomas, J. (ed.) 2000, Interpretive Archaeology: a Reader, Leicester University Press, London. Tilley, C. 1994, A Phenomenology of Landscape. Places, Paths and Monuments, Berg, Oxford.

Urton, G. 1981, At the Crossroads of the Earth and Sky. An Andean Cosmology, University of Texas Press, Austin.

Vaiškūnas, J. (ed.) 2008, Astronomy and Cosmology in Folk Traditions and Cultural Heritage, Archaeologia Baltica 10, Klaipèda University Institute of Baltic Sea Region History and Archaeology, Klaipeda.

Whitley, D. S. 2006, Issues in archaeoastronomy and rock art. In T. W. Bostwick \& B. Bates (eds) 2006, Viewing the Sky through Past and Present Cultures, Pueblo Grande Museum Anthropological Papers no. 15, City of Phoenix, Phoenix, pp. 85-102.

Xu F. \& He N. 2010, Taosi observatory, China. In C. L. N. Ruggles \& M. Cotte (eds), Heritage Sites of Astronomy and Archaeoastronomy in the Context of the UNESCO World Heritage Convention. A Thematic Study, ICOMOS-IAU, Paris, pp. 86-90. 